\title{
Methodologies for the evaluation of the antibacterial activity of propolis
}

\author{
Andresa Piacezzi Nascimento ${ }^{1 *}$, Nathália Ursoli Ferreira ${ }^{1}$, Edna Aparecida Barizon ${ }^{2}$, Bruno \\ Alves Rocha ${ }^{3}$, Mirela Mara de Oliveira Lima Leite Vaz $^{3}$ and Andresa Aparecida Berretta ${ }^{3,4}$ \\ ${ }^{1}$ Laboratory of Microbiology, Apis Flora Indl Coml Ltda., Ribeirão Preto - SP, Brazil. \\ ${ }^{2}$ Laboratory of Clinical Analysis, Faculty of Pharmaceutical Sciences of Ribeirão Preto, University of São Paulo, \\ Ribeirão Preto - SP, Brazil. \\ ${ }^{3}$ Laboratory of Research, Development and Innovation, Apis Flora Indl Coml Ltda., Ribeirão Preto - SP, Brazil. \\ ${ }^{4}$ Laboratory of Molecular Biology, Faculty of Pharmaceutical Sciences of Ribeirão Preto, University of São Paulo,
} Ribeirão Preto - SP, Brazil.

Accepted 26 April, 2013

\begin{abstract}
Currently, there is a global interest in propolis research due to its various biological activities. In vitro methods are useful for preliminary investigation of the antibacterial activity of propolis extracts. The disk diffusion method and broth macrodilution method recommended by the Clinical and Laboratory Standards Institute were used in this study, with some modifications, to evaluate the antibacterial activity of propolis. Staphylococcus aureus ATCC 25923, Pseudomonas aeruginosa ATCC 27853 and Streptococcus pneumoniae ATCC 49619 were used. A standardized extract of Brazilian propolis was evaluated. The methods were precise and showed $100 \%$ accuracy. Gram positive bacteria were more sensitive to propolis extract than Gram negative bacterium. The validations demonstrated that the disk diffusion method and broth macrodilution method are appropriate for the evaluation of the antibacterial activity of propolis extracts. Therefore, the methodologies validated in this study may be useful tools in propolis research.
\end{abstract}

Key words: Methodologies, validation, antibacterial activity, propolis.

\section{INTRODUCTION}

Propolis has been widely used in many parts of the world since ancient times. Egyptians employed propolis to embalm their dead. Greek and Roman physicians used propolis as an antiseptic and cicatrizant agent (Sforcin and Bankova, 2011). Currently, because of its biological activities, propolis is extensively used as a popular remedy to treat a variety of ailments.Propolis is a resin collected by the bee Apis mellifera from the branches, flowers, pollen, buds and exudates of trees, to which the bees add enzymes and salivary secretions. The global interest in research into propolis is mainly due to its diverse biological activities, such as antibacterial

*Corresponding author. E-mail: piacezzi@gmail.com. Tel: +55-16-3514-4412. Fax: + 55-16-3514-4400. 
(Koo et al., 2000; Bruschi et al., 2006; Jorge et al., 2008; Kouidhi et al., 2010; Ordóñez et al., 2011), antifungal (Bruschi et al., 2006; Cardoso et al., 2010; Dota et al., 2011), antiviral (Shimizu et al., 2011; Urushisaki et al., 2011), antioxidant (Souza et al., 2007), anti-inflammatory, healing activities (Gregory et al., 2002), among others.

The biological properties of propolis are linked to its chemical composition, which varies with the flora of the region visited by the bees and the collection period of the resin. This means that the propolis samples collected in different regions of the world and during different seasons may have distinct biological properties and chemical compositions. Due to this, research is needed that evaluates the chemical composition of propolis and its biological activities. Validated methodologies may be useful tools in this research.

In vitro methods are useful for preliminary investigation of the activities of propolis. There are several laboratory methods that can be used to evaluate the antibacterial activity of antimicrobial agents. Among the standard reference methodologies, there are those recommended by the Clinical and Laboratory Standards Institute (CLSI). In the document M02-A10, the CLSI describes standard techniques of disk diffusion in agar used to determine the in vitro sensitivity of bacteria to antimicrobial agents (CLSI, 2009a). In the document M07-A8, the CLSI describes methods for the determination of minimum inhibitory concentrations (MICs) of aerobic bacteria by broth macrodilution, broth microdilution, and agar dilution (CLSI, 2009b).

The disk diffusion method and broth macrodilution method recommended by the CLSI were used in this study, with some modifications, to evaluate the antibacterial activity of propolis.

\section{MATERIALS AND METHODS}

\section{Microorganisms}

The following microorganisms were used: Staphylococcus aureus ATCC 25923, Pseudomonas aeruginosa ATCC 27853 and Streptococcus pneumoniae ATCC 49619. The strains of bacteria were acquired from the American Type Culture Collection (ATCC).

\section{Propolis extract}

In this study, a green propolis standardized extract $\left(E P P-A F^{\circledR}\right.$, batch 010/08, Apis Flora, Ribeirão Preto-SP, Brazil) was used. EPP-AF ${ }^{\circledR}$ presents $11 \%(\mathrm{w} / \mathrm{v})$ of propolis dry matter and it was chemically characterized in a previous study by our group (Berretta et al., 2012).

\section{Validation of the disk diffusion method}

The equipment used during the validation was calibrated within the period of validity of the calibration.

The $S$. aureus and $P$. aeruginosa were grown on Mueller Hinton agar (Difco, Detroid, MI, USA) and incubated at $35 \pm 2{ }^{\circ} \mathrm{C}$ aerobically for $24 \mathrm{~h}$. The $S$. pneumoniae was inoculated on Mueller Hinton agar with $5 \%$ sheep blood (Plast Labor, Rio de Janeiro-RJ, Brazil) and incubated at $35 \pm 2{ }^{\circ} \mathrm{C}$ in $5 \% \mathrm{CO}_{2}$ for $24 \mathrm{~h}$.

After the incubation period, an inoculum was prepared in a sterile, $0.85 \%$ physiological solution, with turbidity equivalent to a $0.5 \mathrm{McF}$ arland standard (approximately $10^{8} \mathrm{CFU} / \mathrm{ml}$ ). The turbidity was measured by spectrophotometer (Biospectro SP-22, China) at a wavelength of $625 \mathrm{~nm}$. A sterile cotton swab was dipped into the suspension, spun several times and pressed firmly against the inner wall of the tube, above the liquid level, in order to remove any excess inoculum from the swab.

The swab containing the suspension was spread over the surface of agar contained in a plate $(90 \times 15 \mathrm{~mm})$. The procedure was repeated twice to ensure even distribution of inoculum. Mueller Hinton agar was used in the test with $S$. aureus and $P$. aeruginosa. For S. pneumoniae, Mueller Hinton agar with $5 \%$ sheep blood was used.

Paper disks (Laborclin, Pinhais-PR, Brazil) were placed in a sterile flask containing $5 \mathrm{ml}$ of EPP-AF ${ }^{\circledR}$, for $5 \mathrm{~min}$. Following this, the soaked disks were removed using forceps, gently pressed on the wall of the flask in order to remove any excess solution and applied to the agar surface. Each disk was pressed down, so as to ensure complete contact with the surface of the agar.

For the accuracy test, the following disks of antimicrobial agents were evaluated: disk containing $1 \mu \mathrm{g}$ of oxacillin (Cefar, São PauloSP, Brazil) (for $S$. aureus and $S$. pneumoniae) and disk containing $10 \mu \mathrm{g}$ of gentamicin (Cefar, São Paulo-SP, Brazil) (for $P$. aeruginosa).

The plates of $S$. aureus and $S$. pneumoniae were incubated as described previously. The plates of $P$. aeruginosa were incubated at $35 \pm 2^{\circ} \mathrm{C}$ aerobically for $18 \mathrm{~h}$. After the incubation period, the diameters of the zones of inhibition were measured using a ruler.

The experiments were replicated five times for each of the three microorganisms. The accuracy of the method was calculated according to the equation below:

Accuracy $=\frac{\text { Experimental diameter }}{\text { Theoretical diameter }} \times 100$

To determine the precision of the method, the diameters of the zones of inhibition in tests with the EPP-AF ${ }^{\circledR}$ (analyst 1) were measured and the relative standard deviation (RSD) was calculated according to the equation below:

$\mathrm{RSD}=\frac{\text { Standard deviation }}{\text { Mean }} \times 100$

To determine the intermediate precision, a second analyst (analyst 2) performed the method. The difference between the mean of the results of both analysts was calculated according to the equation below:

Difference between the mean $=\frac{I U i-X i \mathrm{I}}{U i} \times 100$

Where $\mathrm{Ui}$ is the mean of the results of analyst 1 and $X i$ is the mean of the results of analyst 2 .

The specificity was demonstrated by the growth of the microorganisms in appropriate media, as described previously. 
Table 1. Determination of the accuracy of the disk diffusion method $(n=5)$.

\begin{tabular}{llccc}
\hline Disk & Microorganism & $\begin{array}{c}\text { Theoretical diameter } \\
(\mathbf{m m})\end{array}$ & $\begin{array}{c}\text { Obtained mean diameter } \pm \mathbf{S D}^{\mathbf{a}} \\
(\mathbf{m m})\end{array}$ & $\begin{array}{c}\text { Accuracy } \\
(\%)\end{array}$ \\
\hline $1 \mu \mathrm{g}$ of oxacillin & S. aureus ATCC 25923 & $18-24$ & $21.4 \pm 0.55$ & 100 \\
$10 \mu$ of gentamicin & P. aeruginosa ATCC 27853 & $16-21$ & $20.8 \pm 0.45$ & 100 \\
$1 \mu \mathrm{g}$ of oxacillin & S. pneumoniae ATCC 49619 & $\leq 12$ & $11.8 \pm 0.45$ & 100 \\
\hline
\end{tabular}

${ }^{a} \mathrm{SD}$, standard deviation.

\section{Validation of the broth macrodilution method}

$S$. aureus, $P$. aeruginosa and $S$. pneumoniae were grown on culture media and incubated as described for the disk diffusion method. After the incubation period, an inoculum was prepared in a sterile, $0.85 \%$ physiological solution, with turbidity equivalent to a $0.5 \mathrm{McF}$ arland standard (approximately $10^{8} \mathrm{CFU} / \mathrm{ml}$ ). The turbidity was measured by spectrophotometer at a wavelength of $625 \mathrm{~nm}$. The suspension was ten-fold diluted in the culture medium (dilutions ranging from $1: 10$ to $1: 100$ ) to give an inoculum of approximately $10^{6} \mathrm{CFU} / \mathrm{ml}$. Mueller Hinton broth (Difco, Detroid, MI, USA) was used in the test with $S$. aureus and $P$. aeruginosa. For $S$. pneumoniae, Mueller Hinton broth supplemented with $5 \%$ lysed horse blood (Ebefarma Biológica e Agropecuária, Cachoeiras de Macacu-RJ, Brazil) was used.

Samples were serially diluted in test tubes $(13 \times 100 \mathrm{~mm})$ with $1 \mathrm{ml}$ of culture medium. After dilutions were made, $1 \mathrm{ml}$ of microbial suspension $\left(10^{6} \mathrm{CFU} / \mathrm{ml}\right)$ was added to each tube. The final inoculum concentration in each test tube was of approximately $5 \times 10^{5} \mathrm{CFU} / \mathrm{ml}$. The final dry propolis extract concentrations ranged from 0.85 to $55 \mathrm{mg} / \mathrm{ml}$, for the tests with EPP-AF ${ }^{\circledR}$.

For the accuracy test, the following antimicrobial agents were evaluated: tetracycline (Inlab, Diadema-SP, Brazil) (for $S$. aureus and S. pneumoniae) and gentamicin (Inlab, Diadema-SP, Brazil) (for $P$. aeruginosa). The final concentrations of tetracycline and gentamicin ranged from 0.06 to $32 \mu \mathrm{g} / \mathrm{ml}$.

Control tubes consisted of the culture medium $(1 \mathrm{ml})$ plus microbial inoculum $(1 \mathrm{ml})$ or culture medium alone $(2 \mathrm{ml})$; these controls were used as growth and sterility controls, respectively. Test and control tubes were incubated aerobically at $35 \pm 2{ }^{\circ} \mathrm{C}$ for $20 \mathrm{~h}$ ( $S$. aureus and $P$. aeruginosa) or $24 \mathrm{~h}$ (S. pneumoniae). After the incubation period, the MIC of tetracycline and gentamicin was determined.

Because of the turbidity that occurred in test broth when EPP. $\mathrm{AF}^{\circledR}$ was diluted in the culture medium, it was not possible to determine the MIC. Therefore, the antimicrobial activity of the EPP$\mathrm{AF}^{\circledR}$ was assessed by means of the minimum bactericidal concentration (MBC), which was determined by subculturing $20 \mu \mathrm{l}$ aliquots from each tube in the broth dilution series onto agar plates. Mueller Hinton agar was used in the test with $S$. aureus and $P$. aeruginosa. For $S$. pneumoniae, Mueller Hinton agar with $5 \%$ sheep blood was used. The plates of $S$. aureus and $P$. aeruginosa were incubated at $35 \pm 2^{\circ} \mathrm{C}$ aerobically for $24 \mathrm{~h}$. The plates of $S$. pneumoniae were incubated at $35 \pm 2^{\circ} \mathrm{C}$ in $5 \% \mathrm{CO}_{2}$ for $24 \mathrm{~h}$. After the incubation period, the MBC was determined. It was defined as the lowest concentration of the sample required to kill the microorganism being tested.

The experiments were replicated five times for each of the three microorganisms. The accuracy of the method was calculated according to the equation below:

\section{Accuracy $=\frac{\text { Experimental MIC }}{\text { Theoretical MIC }} \times 100$}

To determine the precision of the method, the MBC of EPP-AF ${ }^{\circledR}$ (analyst 1) was determined and the RSD was calculated.

To determine the intermediate precision, a second analyst (analyst 2) performed the method. The difference between the mean of the results of both analysts was calculated.

The specificity was demonstrated by the growth of the microorganisms in appropriate media, as described previously.

\section{Statistical analysis}

The data of the antibacterial activity were submitted to the nonparametric Kruskal-Wallis test. The established significance level was $1 \%$.

\section{RESULTS}

In this study, Gram positive bacteria ( $S$. aureus ATCC 25923 and $S$. pneumoniae ATCC 49619) were more sensitive to EPP-AF ${ }^{\circledR}$ than Gram negative bacterium ( $P$. aeruginosa ATCC 27853) $(\mathrm{p}<0.01)$.

The accuracy of the disk diffusion method was $100 \%$ in the five replicates for all microorganisms (Table 1). In the determination of the precision of the disk diffusion method, the RSD was less than $15 \%$ for all microorganisms (Table 2). The results obtained by analyst 1 and analyst 2 (Table 2) were evaluated for the determination of the intermediate precision. The difference between the mean of the results of analyst 1 and analyst 2 was less than $15 \%$ for the three microorganisms (Table 3 ).

In the evaluation of the specificity of the disk diffusion method, all microorganisms grew in the appropriate culture media. $S$. aureus and $P$. aeruginosa grew on Mueller Hinton agar in the five replicates. S. pneumoniae, in turn, grew on Mueller Hinton agar with $5 \%$ sheep blood in all replicates.

The accuracy of the broth macrodilution method was $100 \%$ in the five replicates for all microorganisms evaluated (Table 4).

In the determination of the precision of the broth 
Table 2. Determination of the precision of the disk diffusion method in the evaluation of antibacterial activity of a standardized extract of propolis $(n=5)$.

\begin{tabular}{lcccc}
\hline Microorganism & Analyst & $\begin{array}{c}\text { Mean diameter } \\
(\mathbf{m m})\end{array}$ & SD $^{\mathbf{a}}$ & $\begin{array}{c}\mathbf{R S D}^{\mathbf{b}} \\
(\%)\end{array}$ \\
\hline S. aureus ATCC 25923 & 1 & 10.6 & 0.55 & 5.16 \\
& 2 & 11.0 & 0.00 & 0.00 \\
P. aeruginosa ATCC 27853 & 1 & 6.2 & 0.45 & 7.21 \\
& 2 & 6.0 & 0.00 & 0.00 \\
S. pneumoniae ATCC 49619 & 1 & 11.2 & 0.45 & 3.99 \\
& 2 & 11.2 & 0.45 & 3.99 \\
\hline
\end{tabular}

${ }^{\mathrm{a}} \mathrm{SD}$, standard deviation; ${ }^{\mathrm{b}} \mathrm{RSD}$, relative standard deviation.

Table 3. Difference between the mean of the results of analyst 1 and analyst 2 for the determination of the intermediate precision of the disk diffusion method in the evaluation of antibacterial activity of a standardized extract of propolis.

\begin{tabular}{lccc}
\hline Microorganism & \multicolumn{2}{c}{ Mean of the results $\pm \mathbf{S D}^{\mathbf{a}}$} & $\begin{array}{c}\text { Difference between the means of the } \\
\text { results of the analysts (\%) }\end{array}$ \\
\cline { 2 - 3 } & Analyst 1 & Analyst 2 & \\
\hline $\begin{array}{l}\text { S. aureus } \\
\text { ATCC 25923 }\end{array}$ & $10.6 \pm 0.55$ & $11.0 \pm 0.00$ & 3.77 \\
$\begin{array}{l}\text { P. aeruginosa } \\
\text { ATCC 27853 }\end{array}$ & $6.2 \pm 0.45$ & $6.0 \pm 0.00$ & 3.22 \\
$\begin{array}{l}\text { S. pneumoniae } \\
\text { ATCC 49619 }\end{array}$ & $11.2 \pm 0.45$ & $11.2 \pm 0.45$ & 0 \\
\hline
\end{tabular}

${ }^{\mathrm{a} S D}$, Standard deviation.

macrodilution method, the RSD was $0 \%$ for all microorganisms (Table 5). The results obtained by analyst 1 and analyst 2 were evaluated for the determination of the intermediate precision. The difference between the mean of the results of analyst 1 and analyst 2 was $0 \%$ for the three microorganisms.

In the evaluation of the specificity of the broth macrodilution method, all microorganisms grew in the appropriate culture media.

\section{DISCUSSION}

This study used three different microorganisms: a Gram positive ( $S$. aureus ATCC 25923), a Gram negative ( $P$. aeruginosa ATCC 27853) and a fastidious (S. pneumoniae ATCC 49619), which is also Gram positive. These ATCC strains were chosen because they are among the quality control strains suggested by the CLSI (2011) to monitor the accuracy of the disk diffusion method and broth macrodilution method.

The document M02-A10 of the CLSI (2009a) describes standard disk diffusion techniques used to determine the in vitro sensitivity of bacteria to antimicrobial agents. However, this methodology is used to evaluate only the antimicrobial agents present in paper disks available commercially. The present study used the standard disk diffusion techniques established by the CLSI, with some modifications, to evaluate the antibacterial activity of propolis. Paper disks were placed in a sterile flask containing $5 \mathrm{ml}$ of EPP-AF ${ }^{\circledR}$ for $5 \mathrm{~min}$. This period was sufficient for the paper disk to absorb the extract of propolis. Next, each soaked disk was withdrawn from the flask with the aid of forceps and gently pressed against the wall of the flask in order to remove excess extract from the disk. Each disk was applied to the culture medium surface and pressed so as to ensure complete contact of the disk with the surface of the medium.

In the study by Bruschi et al. (2006), the antimicrobial activity of propolis was determined by agar diffusion using the well technique. This technique uses a double layer of agar system (Grove and Randall, 1955). $25 \mathrm{ml}$ of Brain Heart Infusion agar (base layer) were placed in a Petri dish $(125 \times 25 \mathrm{~mm})$. After solidification of the culture 
Table 4. Determination of the accuracy of the broth macrodilution method $(n=5)$.

\begin{tabular}{llccc}
\hline $\begin{array}{l}\text { Antimicrobial } \\
\text { agent }\end{array}$ & Microorganism & $\begin{array}{c}\text { Theoretical MIC } \\
(\mu \mathrm{g} / \mathrm{ml})\end{array}$ & $\begin{array}{c}\text { Obtained mean MIC } \pm \\
\mathbf{S D}^{\mathbf{a}}(\mu \mathbf{g} / \mathbf{m l})\end{array}$ & $\begin{array}{c}\text { Accuracy } \\
(\%)\end{array}$ \\
\hline Tetracycline & $\begin{array}{l}\text { S. aureus } \\
\text { ATCC 25923 }\end{array}$ & $\leq 4$ & $0.25 \pm 0.00$ & 100 \\
Gentamicin & $\begin{array}{l}\text { P. aeruginosa ATCC } \\
27853\end{array}$ & $\leq 4$ & $0.25 \pm 0.00$ & 100 \\
Tetracycline & $\begin{array}{l}\text { S. pneumoniae ATCC } \\
49619\end{array}$ & $\leq 2$ & $0.25 \pm 0.00$ & 100 \\
\hline
\end{tabular}

${ }^{a} \mathrm{SD}$, Standard deviation.

Table 5. Determination of the precision of the broth macrodilution method in the evaluation of antibacterial activity of a standardized extract of propolis $(n=5)$.

\begin{tabular}{lcccc}
\hline Microorganism & Analyst & $\begin{array}{c}\text { Mean MIC } \\
\text { (\% dry propolis extract) }\end{array}$ & SD $^{\mathbf{a}}$ & $\begin{array}{c}\text { RSD }^{\mathbf{b}} \\
(\%)\end{array}$ \\
\hline S. aureus ATCC 25923 & 1 & 0.34 & 0.00 & 0.00 \\
& 2 & 0.34 & 0.00 & 0.00 \\
P. aeruginosa ATCC 27853 & 1 & 1.37 & 0.00 & 0.00 \\
S. pneumoniae ATCC 49619 4960.00 & 0.00 \\
& 2 & 1.37 & 0.00 & 0.00 \\
& 1 & 0.17 & 0.00 & 0.00 \\
\hline
\end{tabular}

${ }^{a} \mathrm{SD}$, standard deviation; ${ }^{\mathrm{b}} \mathrm{RSD}$, relative standard deviation.

medium, $12.5 \mathrm{ml}$ of $\mathrm{BHI}$ agar $\left(50^{\circ} \mathrm{C}\right)$ mixed with $2.5 \mathrm{ml}$ microorganism suspension (seed layer) were added. After solidification, the culture medium was pierced with a sterile stainless steel cylinder (internal diameter of $4 \mathrm{~mm}$ ), in order to form wells where the samples were applied. The plates were pre-incubated for $2 \mathrm{~h}$ at room temperature to allow the spread of the samples in the agar. Then, they were incubated at $37^{\circ} \mathrm{C}$ for 24 to $48 \mathrm{~h}$. After the incubation period, the zones of inhibition around the wells were measured $(\mathrm{mm})$.

Koo et al. (2000) also evaluated the antimicrobial activity of propolis using the well technique. As with the disk diffusion method, the results of the well technique are the diameters $(\mathrm{mm})$ of inhibition zones, as both methods have as a principle the diffusion of the sample in agar. The advantage of the disk diffusion method is that it is faster and easier to perform.

The document M07-A8 of the CLSI (2009b) describes standard dilution techniques used to determine the MIC of antimicrobial agents. The broth macrodilution method recommended by the CLSI was used in this study, with some modifications, to evaluate the antibacterial activity of propolis and determine the MBC.

Some researchers evaluated the antimicrobial activity of propolis using the broth microdilution method (Jorge et al., 2008; Kouidhi et al., 2010; Ordóñez et al., 2011). This method uses a small quantity of culture medium, sample and microbial inoculum because it is carried out in microplates (96-well). It is advantageous when there is a limited amount of sample. The disadvantage of the microdilution method is that, due to small quantity of material, there is a big probability of errors during the dilution. In the broth macrodilution method, this probability is lesser, as it uses a bigger quantity of material than the microdilution method. Due to this, in the macrodilution method the costs are slightly higher.

The accuracy represents the systematic error, which is the difference between the expected value and the value obtained. Therefore, for the accuracy test of the disk diffusion method, antimicrobial agent disks which are described in the tables of the CLSI (2011) were used. These tables give the acceptable limits of the diameters of the zones of inhibition of each antimicrobial agent disk for each quality control strain.

These values (theoretical diameters) were compared with the values obtained in this study (experimental diameters) for the calculation of accuracy. For example, for S. aureus ATCC 25923, the diameter of the zone of 
inhibition should be 18 to $24 \mathrm{~mm}$ in the test with the disk of $1 \mu \mathrm{g}$ of oxacillin (CLSI, 2011). For all the microorganisms studied, the experimental diameters were within acceptable limits (theoretical diameters).

The CLSI also describes the acceptable limits of the MICs obtained in tests with quality control strains. These values were used in this study as theoretical MICs for the test of accuracy of the broth macrodilution method. The MICs obtained in this study (experimental MICs) were compared with the theoretical MICs described by CLSI (2011). For all the microorganisms evaluated, the experimental MICs were within acceptable limits.

The precision of microbiological methods is usually measured by standard deviation (SD) or RSD, the last of which shall be a maximum of 15 to $35 \%$ (United States Pharmacopeia, 2009). Therefore, the RSD values obtained by analyst 1 were within the acceptance criteria in the disk diffusion method and broth macrodilution method.

The intermediate precision aims to analyze the structural variations intrinsic to the laboratory and its influence on the final results of the analytical process. Therefore, the methods were performed by different analysts to determine their degree of precision. In the tests with the three microorganisms, the results obtained by both analysts were precise in both methods. In the broth macrodilution method, the difference between the mean of the results of analyst 1 and analyst 2 was $0 \%$ for the three microorganisms, that is the means of the results of both analysts were identical.

The specificity represents the ability of the method to be specific for the analysis of the microorganism in question. The specificity was demonstrated by the growth of the microorganisms in the appropriate media. Mueller Hinton agar is considered the best culture medium for routine tests of sensitivity against non-fastidious bacteria (CLSI, 2009a) such as $S$. aureus and $P$. aeruginosa. For fastidious bacteria, other culture media are used. For example, for $S$. pneumoniae and other streptococci, Mueller Hinton agar supplemented with $5 \%$ defibrinated sheep blood (CLSI, 2009a) is recommended. In the broth macrodilution method, Mueller Hinton broth is considered the best culture medium for tests of sensitivity against non-fastidious bacteria. For S. pneumoniae and other streptococci, Mueller Hinton broth supplemented with 5\% lysed defibrinated horse blood (CLSI, 2009b) is recommended.

In this study, Gram positive bacteria were more sensitive to EPP-AF ${ }^{\circledR}$ than Gram negative bacterium. In a study by Jorge et al. (2008), Brazilian propolis samples were efficacious against Gram positive bacteria ( $S$. aureus and Kocuria rhizophila), however, none of the samples was active against Gram negative bacteria ( $P$. aeruginosa and Escherichia coli).

Since the beginning of propolis research, several groups have studied its antimicrobial properties. These properties are linked to its chemical composition, which varies with the flora of the region visited by the bees and the collection period of the resin. For example, propolis samples from South America, Europe, and Asia have different chemical compositions. In Brazil, propolis from different geographical regions has different chemical compositions, due to diversity of plant species (Jorge et al., 2008). Therefore, research is needed that evaluates the chemical composition of propolis and its biological activities for the standardization of propolis and development of new drugs. Validated methodologies may be useful tools in this research.

In vitro methods are useful for preliminary investigation of the antibacterial activity of propolis extracts. The disk diffusion method is an excellent method to carry out a screening of different samples of propolis. After the screening, the best samples may be evaluated by the broth macrodilution method to determine the MBC.

In conclusion, Gram positive bacteria were more sensitive to EPP-AF ${ }^{\circledR}$ than Gram negative bacterium. The validations of the methodologies were assured by running tests of accuracy, precision, intermediate precision and specificity. The results of these tests were within the acceptance criteria. Therefore, the validations showed that the disk diffusion method and broth macrodilution method are appropriate for the evaluation of the antibacterial activity of propolis extracts. The methodologies validated in this study may be useful tools in propolis research.

\section{ACKNOWLEDGEMENTS}

The authors thank Conselho Nacional de Desenvolvimento Científico e Tecnológico for the financial support and Apis Flora Indl. Coml. Ltda. for the EPP-AF ${ }^{\circledR}$ provided.

\section{REFERENCES}

Berretta AA, Nascimento AP, Bueno PCP, Vaz MMOLL, Marchetti JM (2012). Propolis standardized extract (EPP-AF®), an innovative chemically and biologically reproducible pharmaceutical compound for treating wounds. Int. J. Biol. Sci. 8:512-521.

Bruschi ML, Lara EHG, Martins CHG, Vinholis AHC, Casemiro LA, Panzeri H, Gremião MPD (2006). Preparation and antimicrobial activity of gelatin microparticles containing propolis against oral pathogens. Drug Dev. Ind. Pharm. 32:229-238.

Cardoso RL, Maboni F, Machado G, Alves SH, Vargas AC (2010). Antimicrobial activity of propolis extract against Staphylococcus coagulase positive and Malassezia pachydermatis of canine otitis. Vet. Microbiol. 142:432-434.

CLSI-Clinical and Laboratory Standards Institute (2009a). Performance standards for antimicrobial disk susceptibility tests; Approved Standard - Tenth Edition. CLSI document M02-A10.

CLSI-Clinical and Laboratory Standards Institute (2009b). Methods for dilution antimicrobial susceptibility tests for bacteria that grow 
aerobically; Approved Standard - Eighth Edition. CLSI document M07-A8.

CLSI-Clinical and Laboratory Standards Institute (2011). Performance standards for antimicrobial susceptibility testing. Twenty-first informational supplement. CLSI document M100-S21.

Dota KFD, Consolaro MEL, Svidzinski TIE, Bruschi ML (2011). Antifungal activity of Brazilian propolis microparticles against yeasts isolated from vulvovaginal candidiasis. Evid. Based Complement. Alternat. Med. 2011:201953.

Gregory SR, Piccolo N, Piccolo MT, Piccolo MS, Heggers JP (2002). Comparison of propolis skin cream to silver sulfadiazine: a naturopathic alternative to antibiotics in treatment of minor burns. $J$. Altern. Complement. Med. 8:77-83.

Grove DC, Randall WA (1955). Assay Method of Antibiotics, Medical Encyclopedia Inc., New York, pp. 188-196.

Jorge R, Furtado NAJC, Sousa JPB, da Silva Filho AA, Gregório Junior LE, Martins CHG, Soares AEE, Bastos JK, Cunha WR, Silva MLA (2008). Brazilian propolis: seasonal variation of the prenylated $p$ coumaric acids and antimicrobial activity. Pharmaceut. Biol. 46:889893.

Koo H, Gomes BPFA, Rosalen PL, Ambrosano GMB, Park YK, Cury JA (2000). In vitro antimicrobial activity of propolis and Arnica montana against oral pathogens. Arch. Oral Biol. 45:141-148.

Kouidhi B, Zmantar T, Bakhrouf A (2010). Anti-cariogenic and antibiofilms activity of Tunisian propolis extract and its potential protective effect against cancer cells proliferation. Anaerobe 16:566571.
Ordóñez RM, Zampini IC, Nieva Moreno MI, Isla MI (2011). Potential application of Northern Argentine propolis to control some phytopathogenic bacteria. Microbiol. Res. 166:578-584.

Sforcin JM, Bankova V (2011). Propolis: is there a potential for the development of new drugs? J. Ethnopharmacol. 133:253-260.

Shimizu T, Takeshita Y, Takamori Y, Kai H, Sawamura R, Yoshida H, Watanabe W, Tsutsumi A, Park YK, Yasukawa K, Matsuno K, Shiraki $\mathrm{K}$, Kurokawa M (2011). Efficacy of Brazilian propolis against herpes simplex virus type 1 infection in mice and their modes of antiherpetic efficacies. Evid. Based Complement. Alternat. Med. 2011:976196.

Souza RM, de Souza MC, Patitucci ML, Silva JFM (2007). Evaluation of antioxidant and antimicrobial activities and characterization of bioactive components of two Brazilian propolis samples using a $\mathrm{pK}_{\mathrm{a}}$ guided fractionation. Z. Naturforsch. C 62:801-807.

United States Pharmacopeia (2009). 32 NF 27, Cap. 1223 Validation of alternative microbiological methods.

Urushisaki T, Takemura T, Tazawa S, Fukuoka M, Hosokawa-Muto J, Araki Y, Kuwata K (2011). Caffeoylquinic acids are major constituents with potent anti-influenza effects in Brazilian green propolis water extract. Evid. Based Complement Alternat. Med. 2011:254914. 